\title{
EL ESPÍA DE LOS ESPÍAS: GORDON THOMAS
}

\section{Rosario Carrizosa Calle}

El escritor galés Gordon Thomas es mundialmente reconocido por sus contactos con los servicios de inteligencia más importantes del mundo. Su manejo de fuentes ultrasecretas y su trato con personalidades que ostentan el poder en todas las esferas le han permitido realizar investigaciones de rigor sobre operaciones de inteligencia del fascinante mundo del espionaje.

Las más de cuarenta obras de Gordon Thomas reposan en manos de alrededor de cuarenta y cinco millones de lectores de todo el mundo y han merecido reconocimientos y menciones tan importantes como el Premio de la Crítica y del Jurado en el Festival de Cine de Montecarlo, el Premio Edgar Allan Poe y tres menciones de la Mark Twain Society, por su labor periodística. Asimismo, ha realizado guiones cinematográficos, en especial la adaptación de su libro El Mossad, que llegará a la pantalla gigante posiblemente a finales del 2005.

El también autor del libro Las torturas mentales de la CIA y Semillas de odio,
Las más de cuarenta obras de Gordon Thomas reposan en manos de alrededor de cuarentay cinco millones de lectores de todo el mundo.

\section{RESUMEN}

El famoso escritor irlandés Gordon Thomas concedió una entrevista a Poliantea en la que comparte sus experiencias como investigador del mundo ultrasecreto del espionaje. El autor del libro Las torturas mentales de la CIA, Semillas de odioy El Mossad, entre otros, ha vendido más de cuarenta y cinco millones de libros a lo largo de su carrera, y se ha convertido en un apoyo fundamental para los servicios de inteligencia más importantes del mundo.

En esta entrevista, Thomas nos acerca al mundo del espionaje y nos introduce en un apasionado relato sobre el manejo de archivos secretos, las fuerzas del poder y el terrorismo.

\section{ABSTRACT}

The famous irish writer Gordon Thomas granted Poliantea an interview in which he shares his experiences as researcher of the ultra secret world of espionage. The author of CIA mental tortures, Hate Seeds and the Mossad, among others, has sold more than forty - five million of books throughout his career, and has become a fundamental support for the most important worldwide intelligence services.

In this interview, Thomas gets us closer to the espionage world and introduces us into a passionate about secret files handling, power forces and even terrorism. 
concedió una entrevista a Poliantea en la que habla de su inquieta carrera y relata algunas experiencias que ha tenido tras sumergirse en el apasionante, pero también peligroso mundo del espionaje.

Poliantea: ¿Cuál ha sido la historia más importante que como periodista ha cubierto?

Gordon Thomas: Sin ninguna duda, la primicia que obtuve del Presidente Nasser sobre la nacionalización del canal de Suez. Esta noticia me lanzó profesionalmente. Es una historia extraordinaria pues en esa época yo era muy joven y trabajaba como periodista en un diario de Londres. Mi papá conocía a Nasser y un día a las siete de la noche, recibí una llamada en la que me informaban que Nasser quería hablar conmigo, que deseaba concederme una entrevista. Viajé a Egipto y enseguida fui a reunirme con el Presidente. Recuerdo que llegué a un lugar muy amplio, en el que me recibieron unos guardias quienes, incluso, me dijeron cómo debía comportarme en la entrevista. Prácticamente no tenía derecho a hablar, y este momento que viví me hace recordar una película de Charles Chaplin, llamada El Dictador. Me senté frente a un escritorio muy grande y ahí apareció Nasser quien sin ninguna antesala se dirigió a mí y me dijo: “Tengo la intención de nacionalizar el canal de

\section{RESEÑA DEAUTOR}

Rosario Carrizosa Calle, actualmente se desempeña como subdirectora del Departamento de Comunicaciones y Editorial del Politécnico Grancolombiano. Ha realizado artículos para diferentes publicaciones, entre ellas, las revistas Fucsia y Cromos; además, escribió para el periódico El Tiempo, en la página social, por un periodo de dos años. En el año 2000, trabajó en la investigación: Pandillas, violencia y drogas, invitada por el programa presidencial Rumbos.
Suez a partir de mañana a las seis de la mañana, solo quiero informarle esto".

\section{P: Luego de recibir esta información, ¿qué le preguntó a Nasser?}

GT: Yo me sentí como un secretario pues no me dejaron hacer preguntas y en esa época todavía no existían las grabadoras de bolsillo, así que sólo me limité a escucharlo y a grabar en la mente textualmente sus palabras.

\section{P: Después de obtener esta información de primera mano, ¿qué hizo usted?}

GT: Salí directo a mi hotel y envié un cable al periódico para contar lo que acababa de escuchar. Sabía que era una primicia y en esa época no había internet, entonces la comunicación era por el sistema viejo de telex. Me puse en contacto con el dueño del periódico que era el mismo editor. En la noche recibí una llamada de él; me decía que estaba loco, que si sabía lo que estaba diciendo y lo importante que era esa noticia. Me dijo que si yo estaba seguro ya mismo cambiaban la primera página del periódico y sacaban esa noticia con foto mía. Pero me advirtió que era muy delicada esa noticia y que si estaba seguro, porque que si el diario publicaba eso y no pasaba, era perder credibilidad y desde luego, yo perdía mi puesto y mi futuro como periodista.

\section{P: ¿Publicaron la noticia?}

GT: A las cuatro de la mañana recibí otra llamada del director del periódico y me dijo que ya había hablado con el gobierno egipcio y que estaban negando toda esta información que yo había dado. Me preguntaron una vez más si yo estaba seguro 
de ello y más o menos me dijeron que si eso no pasaba yo debía irme a vivir a un desierto. Efectivamente, a las seis de la mañana ya estaba nacionalizado el canal de Suez y la primicia la dio el diario.

P: Aparte de lo anterior, ¿cuál ha sido el secreto más grande que usted ha revelado?

GT: Yo pienso que el hecho de que Israel posea armas nucleares. Aunque hay muchas historias, como por ejemplo, las que tienen que ver con la muerte de la Princesa de Gales. Antes de que se revelaran algunos asuntos sobre este particular, yo tuve información de inteligencia muy delicada, que incluso ya he develado en mi libro El Mossad.

\section{$\mathrm{P}:$ ¿Cuáles son esas revelaciones que usted hace en su libro?}

GT: En particular la historia de la princesa Diana me ha intrigado por varias razones que expongo en el libro. Una de ellas es que al final de sus días la princesa estaba trabajando en la campaña de minas antipersonales, tenía una relación afectiva con Dodi Al Fayed y en ese momento la agencia de inteligencia de Israel tenía intereses y estaban ejerciendo presión sobre muchas personas, en particular sobre el conductor de la princesa, Jenry Paul, quien conducía el vehículo que la llevó a la muerte. Esta persona tenía problemas con el alcohol, era una persona vulnerable, así que el Mossad envió a Francia un agente o katsa con el fin de reclutar a Paul como informante para que diera cuenta de los movimientos de personas importantes, como la princesa. Por otro lado, se veía una amenaza sobre la vida de Diana y ella estaba enterada de esto, tanto así que ella grabó seis cintas en las que revela los nombres de todas las personas que en ese momento consideraba que podrían atentar contra su vida. Estas amenazas venían de diferentes grupos; entre ellas de la CIA, y de la inteligencia británica, la MI6.

P: ¿Usted cómo se enteró de esta información?

GT: Yo tengo muy buenas fuentes de inteligencia y descubrí esto por información que recibí de algunas de estas agencias. Esas cintas existen y están guardadas en un lugar muy secreto en los Estados Unidos. Allí también se revelan asuntos que afectan directamente a la familia real y que suponen una relación muy estrecha entre el Principe Carlos y su asistente personal, el señor Fawles.

\section{P: ¿Ha recibido alguna presión para no} hacer públicas sus investigaciones?

GT: Realmente no y por varias razones. Mis fuentes son muy buenas y mi información es responsable. Yo poseo mucha información, pero tengo claro hasta donde llegar, qué debe ser informado y que no. Hay muchas cosas que yo conozco que comprometen la seguridad nacional.

\section{P: La seguridad nacional ¿de qué país?}

GT: De muchos países del mundo. Hablar de ciertas cosas o revelar algunos asuntos puede ser una catástrofe y tener implicaciones que comprometan la seguridad del mundo. Pero les digo, yo no estoy de acuerdo con el periodismo amarillista, algo típico en los diarios ingleses que se conocen como tabloides, donde simplemente publican chivas sin ninguna base o sustento. Mi periodismo es 
A mime

han puesto

toda clase de rótulos. $\mathrm{Me}$

han llamado agente de la CIA, agente del Mossad, de la Agencia Británica. Pero lamento informarles que no soy ningún agente de inteligencia de alguna de estas organizaciones. ante todo investigativo y deseo mantener mis fuentes de información. Por ejemplo, hacer el libro El Mossad me tomó dos años y medio de trabajo con grupos de inteligencia y al publicarlo no recibí ninguna queja de nadie, ninguna amenaza y nadie me ha retirado la confianza que me ofrece. Esto es una prueba de que es un trabajo responsable. Yo soy consciente de que la información que manejo es secreta y que hay un sistema de cooperación de los organismos de inteligencia; sin embargo, la idea es que se informe al público pero de una manera responsable. Yo fui a Colombia invitado por el DAS para dar una conferencia precisamente sobre este punto: Cómo puede trabajar la inteligencia de ustedes en cooperación con la prensa.

P: En su opinión, ¿cuál es el servicio de inteligencia más estructurado del mundo?

GT: Yo diría que el número uno es el Mossad; el segundo, el Servicio Secreto Británico MI6, el tercero la CIA y un cuarto podría ser la BMD de Alemania. Si comparamos el DAS colombiano con el Mossad, ustedes tienen más o menos siete mil agentes y son muy pocos los que hablan dos o tres idiomas, en cambio el grupo del Mossad israelí son mil quinientas personas, pero entre ellos hay muchos que hablan 39 idiomas. Además aprovechan su diáspora judía y diariamente cada persona va leyendo, se va informando por los medios de comunicación y están en permanente contacto unos y otros. Este servicio de inteligencia, por ejemplo, funciona como un rompecabezas, en el que se pretende unir todas las piezas para que al final todo vaya coordinado.
P: ¿Cuántos agentes del Mossad están en Colombia?

GT: Esa cifra no se puede obtener, pero los suficientes para estar bien informados.

P: Usted ha mencionado que a raíz de su libro Semillas de odio los servicios de inteligencia del mundo lo consultan con frecuencia para ratificar información. ¿Quiénes lo contactan con frecuencia?

GT: Este libro, en la edición en idioma inglés, publicó 120 páginas de documentos que respaldan el libro. Esto hace que me tomen en serio y entonces agencias como el FBI, la CIA y las agencias de Francia y Alemania me han llamado para que les dicte conferencias y los apoye. Entre estos servicios y yo hay una gran cooperación.

P: Existe la posibilidad de que algunos lectores llegasen a pensar que usted mismo es un agente secreto de alguna de estas agencias. ¿Qué responde a ello?

GT: A mi me han puesto toda clase de rótulos. Me han llamado agente de la CIA, agente del Mossad, de la Agencia Británica. Pero lamento informarles que no soy ningún agente de inteligencia de alguna de estas organizaciones.

P: ¿No ha llegado usted a pensar que la información que le dan las mismas agencias puede ser un sofisma de distracción creado por ellas mismas para causar confusión?

GT: Me parece muy buena la pregunta. Y puedo decir que al recibir alguna información yo la reviso con otras fuentes. Yo puedo identificar la autenticidad de los documentos que manejo y si las distintas informaciones que recibo están entrelaza- 
das no tengo razón para dudar o no creer en su veracidad.

P: Cambiando de tema, ¿qué sabe usted de una posible relación entre Al Qaeda y las FARC?

GT: Esta es información que poseen varias inteligencias; la de Washington, la colombiana y la de Londres. Se han encontrado documentos en Arabia Saudita que señalan estrechos lazos entre Al Qaeda y las FARC. Estos documentos hablan sobre reuniones sostenidas entre estos grupos y la razón es que Al Qaeda está interesada en América Latina, porque encuentra que es un terreno muy fértil y que se puede explotar la pobreza para fines terroristas. Personalmente he visto estos documentos y algunos otros de las agencias de inteligencia británica y estadounidense. Esas son mis fuentes al respecto.

\section{P: Según usted, ¿qué va a pasar con Colombia frente al terrorismo?}

GT: La situación de Colombia es realmente muy peligrosa, más de lo que ustedes pueden suponer. Aquí existe terrorismo, pero además están rodeados por él, en Bolivia, Venezuela, Perú, y en otros países cercanos. Hace un tiempo algunos grupos al margen de la ley de estos países, incluido México hicieron una reunión en ciudad de México. La idea de estas organizaciones era establecer sus redes del terror. Lo que necesita Colombia más que dinero es el apoyo en equipos. Asimismo el país necesita escuchar.

$\mathrm{P}:{ }^{\mathrm{¿} A}$ qué se refiere cuando dice el país necesita escuchar?

GT: El DAS debe aprender el idioma que hablan los terroristas, así que no pueden defenderse únicamente con el español.
Por ejemplo, la agencia del DAS debería enseñar al menos 18 idiomas, entre ellos los que se hablan en el Medio Oriente, para poder estar en los mismos términos que estos delincuentes. Ustedes deben mantener contactos con otros servicios de inteligencia, no limitarse a la CIA o el FBI. Las relaciones ahora se dan a través de las embajadas con algunos países y yo creo que ustedes deben acercarse y buscar cooperación con otras agencias del mundo. A medida que nos alejamos de septiembre 11 nos acercamos a un segundo atentado. En cualquier momento puede suceder algo y no sabemos donde.

P: En algunas entrevistas que usted ha concedido afirma que grupos terroristas como Al Qaeda busca intercambiar conocimientos con grupos terroristas de América Latina. ¿De qué tipo de intercambio estamos hablando?

GT: Al Qaeda es una nueva fuerza que lo que desea conseguir es el poder. En otras palabras ellos quieren limpiar al mundo de América, pues para ellos todo lo que no corresponde al mundo islámico es el enemigo. Ellos se ven así mismos como luchadores de la libertad. En algunos lugares de Europa se tiene una idea un poco romántica de que las FARC son como Robin Hood, pero ellos están totalmente asociados con el manejo de las drogas y el narcoterrorismo. También puedo decir que China está cooperando con el terrorismo y si ustedes recuerdan, China cooperó con Irak, Irán, y Pakistan en cuestiones terroristas. China también tiene intereses en América y en esa reunión efectuada en México que mencionaba anteriormente, alguien indicó que en República
Se han encontrado documentos en Arabia Saudita que señalan estrechos lazos entre Al Qaeday las FARC. Estos documentos hablan sobre reuniones sostenidas entre estos grupos y la razón es que Al Qaeda está interesada en América Latina, porque encuentraque es un terreno muy fértily que se puede explotar la pobreza parafines terroristas. 
Dominicana se encontraban estudiantes, muchos de ellos afines con el islamismo, entonces yo creo que esto es una bomba de tiempo. No sabemos en qué momento estos jóvenes se vuelvan fanáticos y quizás en cinco años tengamos ya gente suicida. Recordemos quién era Bin Laden. Era un ingeniero muy habilidoso y no se preveía una base religiosa en su personalidad.

\section{P: ¿Usted sabe dónde está Bin Laden?}

GT: Con seguridad está escondido (risas). Es muy factible que se encuentre en China.

P: Hace unos años usted entrevistó a Sadam Hussein, cuando estaba en el poder. ¿Qué opinión le mereció este personaje?

GT: Al final de la guerra Irán-Irak tuve la oportunidad de entrevistarlo. Me pareció una persona amable y muy inteligente.

P: Un libro suyo que trate sobre las fuerzas terroristas en Colombia puede servir al país para que el mundo, especialmente la comunidad europea, vea la realidad de nuestros grupos subversivos que son ante todo terroristas. ¿ Ha pensado en tocar este tema en una próxima publicación?

GT: Es un tema muy interesante y les puedo adelantar que ya se está cocinando algo al respecto. Mi próximo libro tiene que ver con el terrorismo y seguramente trataré estos grupos.
P: Según usted, ¿que país representa una amenaza para el mundo, en especial en un futuro cercano?

GT: El mundo debe dirigir su mirada a China. Las razones están en mi libro Semillas de odio, pero les puedo decir que la conexión de China con el terrorismo internacional es indiscutible y que es una potencia que se está aprovechando de la crisis mundial para convertirse en una superpotencia que atente contra Occidente. En este libro, doy a conocer un pequeño documento escrito por el director de la CIA, George Tenet dirigido al presidente Bush, en el cual dice que miembros de la agencia de inteligencia creen que para el año 2015 Estados Unidos tendrá que enfrentar decenas de armas nucleares procedentes de China. Por lo cual el país está reconstruyendo sus sistemas de defensa, incluyendo el programa Guerra de las Galaxias.

Las pruebas encontradas muestran que China sí proveyó a Irak, a Irán y a Pakistán con armas, incluyendo la llamada bomba islámica y que ha ayudado a Corea del Norte.

Los documentos hallados muestran que China trabaja a través de otros países para debilitar a Estados Unidos y al mismo tiempo con el propósito de construir sus propias bases en el Medio Oriente. 